\title{
Colistin resistance of non-pathogenic strains of Escherichia coli occurring as natural intestinal flora in broiler chickens treated and not treated with colistin sulphate
}

\author{
Michał Majewski ${ }^{1 凶}$, Anna Łukomska², Jarosław Wilczyński³ \\ Danuta Wystalska ${ }^{3}$, Przemysław Racewicz ${ }^{1}$, Joanna Nowacka-Woszuk ${ }^{4}$, \\ Marcin Pszczola ${ }^{4}$, Krzysztof Anusz $^{5}$ \\ ${ }^{1}$ Laboratory of Veterinary Public Health Protection, Faculty of Veterinary Medicine and Animal Science, \\ University of Life Sciences in Poznań, 62-002 Złotniki, Poland \\ ${ }^{2}$ Department of Preclinical Sciences and Infectious Diseases, ${ }^{4}$ Department of Genetics and Animal Breeding, \\ Faculty of Veterinary Medicine and Animal Science, University of Life Sciences in Poznań, 60-637 Poznań, Poland \\ ${ }^{3}$ Lab-Vet Laboratory, 62-080 Tarnowo Podgórne, Poland \\ ${ }^{5}$ Department of Food Hygiene and Public Health Protection, Institute of Veterinary Medicine, \\ Warsaw University of Life Sciences-SGGW, 02-787 Warsaw, Poland \\ michalm@up.poznan.pl
}

Received: February 23, 2020 Accepted: August 27, 2020

\begin{abstract}
Introduction: A significant threat to public health is presented by antibiotic-resistant strains of bacteria, selective pressure on which results from antibiotic use. Colistin is an antibiotic commonly used in veterinary medicine, but also one of last resort in human medicine. Since the 2015 discovery in China of the $\mathrm{mcr}-1$ gene encoding colistin resistance in Enterobacteriaceae, other countries have noted its presence. This study was to find the $m c r-1$ gene prevalence in $E$. coli isolated from poultry slaughtered in Poland. Material and Methods: Cloacal swabs were taken from December 2017 to October 2018 from broiler chickens in three regions. The samples $(n=158)$ were grouped as flocks treated with colistin sulphate $(n=87)$ and those not treated $(n=71)$. Resistance to antimicrobials commonly used in poultry was evaluated by minimum inhibitory concentration. The presence of the $m c r-1$ gene was confirmed by PCR. Results: Isolates containing the $m c r-1$ gene were yielded by $11.27 \%$ of the samples from not treated flocks and $19.54 \%$ of those from treated flocks, but no statistically significant difference in the prevalence of the gene was seen between the groups. Conclusion: The results clearly preclude intensification of selective pressure for colistin resistance due to colistin sulphate treatment because they show that the avian gastrointestinal tract was already inhabited by colistin-resistant E. coli by the time the chickens came to the poultry house.
\end{abstract}

Keywords: poultry, Escherichia coli, antibiotic resistance, colistin.

\section{Introduction}

The presence of antibiotic-resistant bacterial strains in farm animals used for food production presents a significant public health challenge. Since 2015, when the plasma-transferred mor-1 gene encoding for colistin resistance was discovered for the first time in China, there have been an increasing number of reports reflecting the rapid spread of resistance to this antibiotic (13). Livestock and food of animal origin are among the sources of microorganism transmission into the human body (12). Studies of E. coli resistance to colistin have usually involved strains isolated from pigs (3), but the bacteria inhabiting poultry digestive tracts can also gain resistance. Due to their short fattening period, the risk of bacterial infection in broiler chickens is lower than in other slaughter animals, but antibiotic therapy is frequently necessary during breeding. Chicken tissue is exposed to a risk of contamination and meat to a risk of cross-contamination much more frequently than the tissue and meat of other species. Contamination with 
intestinal flora may occur at many stages, including during breeding, while transferring broilers to the slaughterhouse, or actually on those premises, given that the requirement for fast slaughter and postslaughter processing deprioritises careful procedures and leads to contamination events being quite common. Intestinal injury can lead to the bacteria living in birds' digestive tracts being transferred to the surface of the meat, where it poses a threat to human consumers (17, 23).

In many cases, plasmids transmitting colistin resistance genes also transfer the genes for resistance to carbapenems and $\beta$-lactams with wide substrate spectrum $(10,19,27)$. Moreover, the mechanism of colistin resistance can be conferred to other bacteria species through horizontal gene transfer. Reports published so far have described such occurrences in Citrobacter braakii, Cronobacter sakazakii, Kluyvera ascorbata and Klebsiella aerogenes, as well as in pathogens that pose serious threats to public health, such as Salmonella enterica and Klebsiella pneumoniae (25).

The most important pathogenic agents in which antibiotic resistance is known and which cause human gastrointestinal tract infections as a result of the consumption of undercooked poultry include Salmonella and Campylobacter jejuni $(6,11)$. The risk posed by antibiotic-resistant non-pathogenic strains of E. coli is much less often discussed, as these bacteria are less likely to cause food poisoning. Public health specialists have been paying increasing attention to the danger of transferring antibiotic resistance genes to other microorganisms. Mobile genetic elements, such as plasmids, are at the root of many such mechanisms. The $m c r-1$ gene, discovered in 2015 in China encoding E. coli resistance to colistin, has been found in the plasmid pHNSHP45, which is classified as an IncI2 plasmid (13). Over the months following the gene's discovery, $m c r-1$-positive strains of $E$. coli were detected in animals and in some rare cases in humans, and were also isolated in other countries. The genes belonging to the $m c r$ group were also localised on plasmids IncI2, IncHI2, and IncX4 $(12,15)$. The growing prevalence of colistin-resistant strains of E. coli is believed to originate from the overuse of colistin sulphate in animal husbandry. Colistin is commonly used globally to treat infections caused by Enterobacteriaceae, and as an antibiotic growth promoter added to feed. Since the increasing prevalence of colistin-resistant strains of E. coli has been detected in animals throughout the world, many governments that had previously taken a liberal approach to antibiotic growth promoter use have moved to ban this antibiotic as a feed additive $(1,12$, 17, 24).

Colistin is a commonly used antibiotic in poultry production in Poland. This study evaluated the effects of medicinal preparations containing colistin sulphate on the incidence of the plasmid $m c r-1$ gene in non- pathogenic strains of $E$. coli in the intestinal flora of healthy broiler chickens intended for slaughter.

\section{Material and Methods}

Study material and isolation of bacterial strain. The study material consisted of cloacal swabs taken from December 2017 to October 2018 from broiler chickens belonging to commercial poultry flocks from the three provinces of Wielkopolskie, Lubuskie, and Zachodniopomorskie. The swabs were collected in two slaughterhouses from dead birds that had previously been stunned in controlled atmosphere system (CAS) chambers and bled, as described in Regulation (EC) $1099 / 2009$ (7). The samples came from flocks treated with colistin sulphate $(n=87)$ or not treated $(n=71)$. A total of 108 samples were collected in the first slaughterhouse (each sample was swabbed from five chickens chosen at random, from 70 treated and 38 not treated flocks), and 50 samples were taken in the second slaughterhouse (also in this instance each sample was swabbed from five chickens chosen at random, from 17 treated and 33 not treated flocks). The managers running these facilities agreed that the samples could be collected under the condition that no data identifying the slaughterhouses and farms be published. For this reason, only the regions in which the farms are located are given.

The samples were collected using NRS II Transwab swabs with $10 \mathrm{~mL}$ of buffered peptone water (Medical Wire \& Equipment, Corsham, UK) from the cloaca of the slaughtered broilers. The material was plated on MacConkey Agar (Oxoid, Basingstoke, UK) supplemented with $2 \mathrm{mg} / \mathrm{L}$ of colistin sulphate (Sigma Aldrich, St. Louis, MO, USA). A stock solution was prepared by dissolving $20 \mathrm{mg}$ of the standard in $5 \mathrm{~mL}$ of $\mathrm{H}_{2} \mathrm{O}$ to a concentration of $4 \mathrm{mg} / \mathrm{mL}$. The working solution was made by mixing the stock solution with water in a $1: 1$ ratio $(2 \mathrm{mg} / \mathrm{mL})$. The plates were incubated for $24 \pm 2 \mathrm{~h}$ under aerobic conditions at $37^{\circ} \mathrm{C}$ $\pm 1^{\circ} \mathrm{C}$. Following the incubation, a single colony with a phenotype typical of $E$. coli growing on MacConkey Agar was passaged to Nutrient Agar (Oxoid) to isolate a pure culture for further testing. The incubation conditions were $37^{\circ} \mathrm{C} \pm 1^{\circ} \mathrm{C}$ and $24 \pm 2 \mathrm{~h}$.

Antimicrobial susceptibility testing by MIC. The minimum inhibitory concentrations (MICs) for antibiotics belonging to different chemical groups such as colistin, amoxicillin, amoxicillin/clavulanic acid, doxycycline, enrofloxacin, florfenicol, neomycin, norfloxacin, spectinomycin, and trimethoprim with sulphamethoxazole were assayed. The cultured colonies were suspended in demineralised water (Trek Diagnostic Systems, Cleveland, OH, USA) to obtain 0.5 McFarland turbidity, as assessed using a Sensititre Nephelometer (Trek Diagnostic Systems). E. coli suspension was spread with a sterile swab on MuellerHinton Agar (Oxoid) and the minimal bacterial growth 
inhibitory concentration was determined using MIC Test Strip gradient strips (Liofilchem, Roseto degli Abruzzi, Italy). The incubation was conducted in an aerobic atmosphere at $35^{\circ} \mathrm{C} \pm 1^{\circ} \mathrm{C}$ for $18-20 \mathrm{~h}$. The results were confirmed using a microdilution method in a Vizion device (Trek Diagnostic Systems). To this end, colonies of the isolates were transferred to $4 \mathrm{~mL}$ of demineralised water (Trek Diagnostic Systems) to achieve a suspension of 0.5 turbidity on the McFarland scale. As previously, the turbidity was measured using a Sensititre Nephelometer (Trek Diagnostic Systems). The $10 \mu \mathrm{L}$ of suspension thus prepared was transferred into $11 \mathrm{~mL}$ of Mueller-Hinton Broth (Trek Diagnostic Systems). The resulting inoculum was placed on a plate at $50 \mu \mathrm{L}$ per well with a Sensititre AutoInoculator (both Trek Diagnostic Systems) and incubated at $37^{\circ} \mathrm{C} \pm 1^{\circ} \mathrm{C}$ for 18-24 h. After incubation, the Sensititre plate was read in the Vizion device using SWIN software (Trek Diagnostic Systems). The MIC results were automatically interpreted by the SWIN software used by the equipment and reagent manufacturers based on FDA, CLSI and EUCAST guidelines.

To confirm MIC for colistin, an additional ComASP Colistin test based on the broth microdilution method (Liofilchem) was conducted, calibrated to MIC between 0.25 and $16 \mu \mathrm{g} / \mathrm{mL}$. Control bacteria were analysed together with reference strains of $E$. coli ATCC 25922, Pseudomonas aeruginosa ATCC 27853, and $E$. coli NCTC 13846. The tests were repeated three times for each isolate. The bacterial suspension, with a density of 0.5 on the McFarland scale, was diluted 1:20 with saline solution. Then, $0.4 \mathrm{~mL}$ of the mixture was transferred to a test tube filled with MuellerHinton II Broth (Liofilchem). Each well of the assay plate was filled with $100 \mu \mathrm{L}$ of the mixture. The plates were incubated at $36^{\circ} \mathrm{C} \pm 2^{\circ} \mathrm{C}$, and the results were read after $18 \mathrm{~h}$.

DNA isolation. The isolated $E$. coli were stored at $-80^{\circ} \mathrm{C}$ on Viabank Medium (Medical Wire \& Equipment). To detect the possible presence of genes encoding colistin resistance, colistin-resistant isolates of E. coli were sieved onto Nutrient Agar (Oxoid) and held at $37^{\circ} \mathrm{C} \pm 1^{\circ} \mathrm{C}$ for $24 \pm 2 \mathrm{~h}$. The control sample was a plasmid gene for E. coli strain ZTA14/01057 received from Visavet Health Surveillance Centre (Complutense University, Madrid, Spain). The negative control was provided by four isolates of $E$. coli not grown on a medium supplemented with colistin sulphate $(2 \mu \mathrm{g} / \mathrm{mL})$, and in which colistin resistance was not detected in a gradient diffusion test. The test was performed for a sample consisting of the living colony dissolved in $50 \mu \mathrm{L}$ of distilled water, denatured for $5 \mathrm{~min}$ at $98^{\circ} \mathrm{C}$ and centrifuged at $10,000 \mathrm{rpm}$. The reaction consumed $3 \mu \mathrm{L}$ of supernatant.

PCR conditions. After obtaining individual living colonies, bacterial DNA was examined using the PCR method. The reaction mixture of $20 \mu \mathrm{L}$ volume contained: $2 \mu \mathrm{L}$ of DNA, $0.3 \mu \mathrm{L}$ of Taq (EurX, Gdańsk, Poland), and $1 \mu \mathrm{L}$ of each starter: F - 5'-CGG
TCAGTCCGTTTGTTC-3' and R - 5'-CTTGGTCGG TCTGTAGGG-3' (13). The PCR conditions were as follows: an initialisation step at $94^{\circ} \mathrm{C}$ for $5 \mathrm{~min}, 35$ cycles of denaturation at $94^{\circ} \mathrm{C}$ for $40 \mathrm{~s}$, annealing at $60^{\circ} \mathrm{C}$ for $40 \mathrm{~s}$, and elongation at $72^{\circ} \mathrm{C}$ for $40 \mathrm{~s}$, and final cooling of the product to $15^{\circ} \mathrm{C}$. The reaction product contained 309 bp and was visualised in electrophoresis in $1.5 \%$ agarose gel. To assess the significance of the differences in the frequency of mcr-1-positive E. coli between samples from flocks treated and not treated with colistin sulphate, Pearson's chi-squared test was carried out on a contingency table, implemented in the chisq.test function in the base package of R statistical software (22).

\section{Results}

Phenotyping using the MIC Test Strip gradient strips and ComASP confirmed the resistance of 25 bacteria to colistin, with $4 \mu \mathrm{g} / \mathrm{mL}$ in 24 strains and $8 \mu \mathrm{g} / \mathrm{mL}$ in one strain.

Colistin-resistant strains of $E$. coli may be present in birds moved to a growing facility on the first day of their lives, or may be carried on contaminated equipment, as they were detected in different poultry houses on the same farm (five samples from different flocks kept in one location) within 47 days between the first and last sampling date. A similar situation occurred for the samples from four groups reared in two buildings at the same location. This means that $52 \%$ of the positive samples came from farms where at least two poultry houses accommodated broilers that carried the $m c r-1$ gene.

All the isolated colistin-resistant $E$. coli showed multidrug resistance. All $25 \mathrm{E}$. coli isolates were resistant to amoxicillin, $28 \% \quad(7 / 25)$ to amoxicillin/clavulanic acid, 24\% (6/25) to doxycycline, $76 \% \quad(19 / 25)$ to enrofloxacin, $64 \% \quad(16 / 25)$ to norfloxacin, $40 \%(10 / 25)$ to florfenicol, $4 \%(1 / 25)$ to neomycin, $40 \%(10 / 25)$ to spectinomycin, and $80 \%$ (20/25) to trimethoprim with sulphomethoxazole. The results of multidrug resistance testing are shown in Table 1.

In addition, $60 \%(15 / 25)$ of $m c r-1$-positive isolates were intermediate susceptible to spectinomycin, $4 \%$ $(1 / 25)$ to norfloxacin, $24 \%(6 / 25)$ to florfenicol, $52 \%$ (13/25) to doxycycline, and $28 \%(7 / 25)$ to amoxicillin with clavulanic acid.

The PCR results indicate the presence of the $\mathrm{mcr}-1$ gene in the 25 colistin-resistant strains (Fig. 1).

$E$. coli with the $m c r-1$ gene plasmid was detected in samples from both slaughterhouses; its prevalence was $17.6 \%$ in the first slaughterhouse and $10 \%$ in the second one. Cloacal swabs from the broilers in slaughterhouse 1 revealed a significantly higher prevalence $(\mathrm{P}=0.02535)$ of $m c r-1$-positive $E$. coli in the flocks treated with colistin sulphate $(21.43 \%$, $15 / 70)$ than in the not treated flocks $(13.16 \%, 5 / 38)$. No 
such difference $(\mathrm{P}=0.6547)$ was seen in slaughterhouse 2, where $m c r-1$ prevalence was $9.09 \%$ in the treated flocks and $11.76 \%$ in the not treated flocks. The prevalence of $m c r-1$-positive strains in the samples from Wielkopolskie Province was 17.43\% (19/109), while in those from Zachodniopomorskie Province it was $15.79 \%$ (6/38). The samples from Lubuskie Province contained no $\mathrm{mcr}-1$ gene, but there were few of these samples $(0 / 11)$. In the flocks where the $m c r-1$ gene was not detected, antibacterial therapy was applied an average of 3.06 times per flock, while in the mcr-1-positive flocks it was applied an average of 2.88 times per flock. Three multidrug-resistant isolates were sensitive only to neomycin and two were partially resistant to spectinomycin and florfenicol.

Table 1. Number of $E$. coli strains resistant to more than two antibiotics

\begin{tabular}{ll}
\hline $\begin{array}{l}\text { Number of } \\
\text { antibiotics: }\end{array}$ & $\begin{array}{l}\text { Percentage of resistant bacteria (number of } \\
\text { strains out of the total 25): } \\
3\end{array}$ \\
\hline 4 & $12 \%(3)$ \\
\hline 5 & $20 \%(4)$ \\
\hline 6 & $28 \%(7)$ \\
\hline 7 & $8 \%(2)$ \\
\hline 8 & $12 \%(3)$ \\
\hline 9 & $4 \%(1)$ \\
\hline
\end{tabular}

No significant difference was observed in the prevalence of the $m c r-1$ gene between the flocks treated with colistin sulphate and those that were not treated $(\mathrm{P}=0.07186)$. In the not treated flocks, $m c r-1$-positive E. coli was isolated in $11.27 \%$ of birds $(8 / 71)$, while in the flocks treated with colistin this was found in $19.54 \%(17 / 87)$. All the results are presented in Table 2.

The farmers' declarations for the tested flocks showed that the most commonly used antibiotics were amoxicillin trihydrate $(80 \%, 20 / 25)$, colistin sulphate $(68 \%, 17 / 25)$, enrofloxacin $(40 \%, 10 / 25)$, doxycycline $(36 \%, 9 / 25)$, sulphamethoxazole with trimethoprim $(36 \%, 9 / 25)$, lincomycin-spectinomycin $(20 \%, 5 / 25)$, florfenicol $(4 \%, 1 / 25)$, and amoxicillin with clavulanic acid (4\%, 1/25).

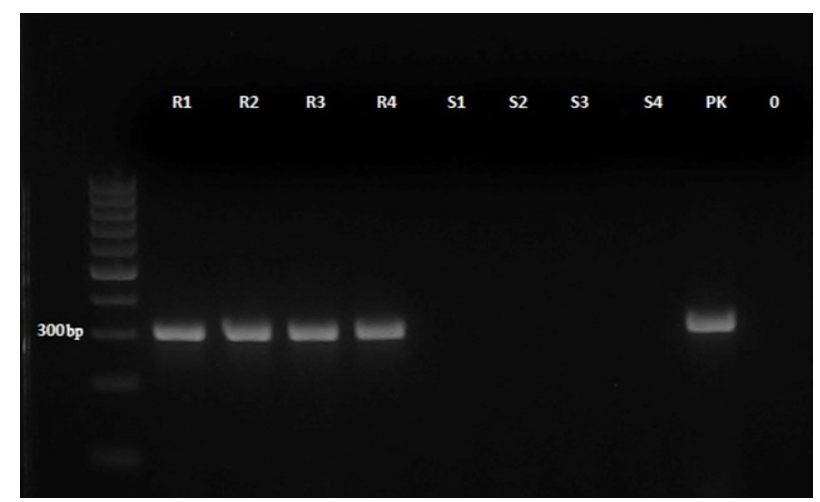

Fig. 1. Electrophoresis for $m c r-1$ gene amplification of E. coli isolates with MIC exceeding $2 \mu \mathrm{g} / \mathrm{mL}$. R1-4 - mcr-1-positive $E$. coli; PK - positive control; S1-4 - negative controls; 0 - sample without DNA

\section{Discussion}

Veterinary medicinal products are commonly used in broiler chickens to reduce losses caused by bacterial infections. Due to the prevalence of infections, antibiotics are the most common, and usually the only, type of pharmaceuticals used.

Only a few of the flocks investigated in this study were not treated over the six-week fattening period. The frequent use of medicines in poultry is a global problem, with different solutions being adopted to treat bacterial infections. In North America, the most commonly used group of drugs is the tetracyclines, which account for two-thirds of all antibiotics given to animals; in Europe, they account for 37\% (2, 23). Our study showed that tetracyclines were rarely used to treat broilers ( $14.56 \%$ of flocks), even though data from the European Medicines Agency indicate that they accounted for $32.2 \%$ of all antibiotics sold in Poland (8). The most commonly used drugs were $\beta$-lactams ( $97 \%$ of flocks), fluoroquinolones ( $56 \%$ of flocks), and polymyxins in the form of colistin (55\% of flocks). Colistin has been recognised as a critically important human antimicrobial by the WHO, so these data on the frequency of its veterinary use are disconcerting (26).

According to the European Medicines Agency, polymyxin (mg/population correction unit - PCU) sales in Poland increased by $35 \%$ between 2011 and 2016. In 2011 they made up $3.3 \%$ of all antibiotics, and in 2016 $4.3 \%$. Colistin is also used in farm animals in other European countries.

Table 2. Number of isolated colistin-resistant $E$. coli in the flocks treated with colistin sulphate and those not treated

\begin{tabular}{lllll}
\hline & Number of flocks (n) & Percentage of flocks & $\begin{array}{l}\text { Number of flocks carrying } \\
m c r-1 \text { gene (n) }\end{array}$ & $\begin{array}{l}\text { Percentage of flocks } \\
\text { carrying } m c r-1 \text { gene }\end{array}$ \\
\hline Not treated (a) & 71 & $44.94 \%$ & 8 & $11.27 \%$ \\
\hline Treated (b) & 87 & $55.06 \%$ & 17 & $19.54 \%$ \\
\hline Total & 158 & $100.00 \%$ & 25 & $15.82 \%$ \\
\hline
\end{tabular}

$\mathrm{a}$ - flocks not treated with colistin sulphate; $\mathrm{b}$ - flocks treated with colistin sulphate 
It is particularly popular in Spain (22.00 $\mathrm{mg} / \mathrm{PCU})$, Italy (15.10 mg/PCU), Portugal (13.53 $\mathrm{mg} / \mathrm{PCU})$, Germany $(7.89 \mathrm{mg} / \mathrm{PCU})$, and Hungary (6.62 mg/PCU). Interestingly, despite its considerable use, polymyxin sales have dropped over the last seven years by $62 \%$ in Italy, $68 \%$ in France, and $47 \%$ in Germany. In this period, polymyxins were not used at all in Finland, Iceland, or Norway, and furthermore, countries where sales were already low, including the United Kingdom $(<0.05 \mathrm{mg} / \mathrm{PCU})$, Sweden $(0.09$ $\mathrm{mg} / \mathrm{PCU})$, Slovenia (0.1 $\mathrm{mg} / \mathrm{PCU})$, Latvia (0.89 $\mathrm{mg} / \mathrm{PCU})$, Lithuania $(0.98 \mathrm{mg} / \mathrm{PCU})$, and the Netherlands $(0.31 \mathrm{mg} / \mathrm{PCU})$, have striven to eliminate this antibiotic from the treatment of livestock (24). In other parts of the world, the use of pharmaceuticals in poultry is also frequent. Of 280 broiler flocks investigated from 2014 to 2016 in Morocco, 93\% were treated for at least three days of the fattening period, usually with enrofloxacin, colistin, and trimethoprim. Colistin was used at $8.40 \mathrm{mg} / \mathrm{kg}(20)$.

The occurrence of antibiotic-resistant bacterial strains is an increasingly serious threat to both human medicine and animal production. The spread of antibiotic resistance among bacteria that inhabit the human body usually happens via their transmission from the environment. This may cause rapid escalation from single cases to a serious threat to public health, as in the case of E. coli ST131 or K. pneumoniae ST258 (16). Mcr-1-positive E. coli as isolated from the digestive tracts of farm animals has quickly spread all over the world and sometimes causes infections in humans. Colistin-resistant strains of E. coli also pose a threat in countries where antibiotic resistance is low. Finland is one of three European countries that does not use polymyxins in veterinary medicine, yet the country's first case of human infection with $E$. coli with the plasmid-transferred $m c r-1$ gene has been reported $(9,12)$. E. coli strains with the plasmid $m c r-1$ gene are most commonly isolated from farm animals, but they also pose a threat to public health, as evidenced by their isolation from other sources. Studies have revealed the highest average prevalence of pathogenic $E$. coli to be in animals $(16.8 \%)$, followed by food $(7.1 \%)$ and humans $(0.7 \%)(5)$. Moreover, the first reports have been published of colistin-resistant $E$. coli producing extended spectrum beta-lactamase being isolated from the environment (29). MIC values for these isolates ranged from 4 to $8 \mu \mathrm{g} / \mathrm{mL}$ and were consistent with data from another study that investigated the resistance of pathogenic $E$. coli from chicken organs to colistin. Of the 13 mcr-1-positive strains isolated between 2004 and 2012 by Yassin et al. (28), 11 (84.6\%) showed resistance to colistin at $4 \mu \mathrm{g} / \mathrm{mL}$, while the other $2(15.4 \%)$ were resistant at $8 \mu \mathrm{g} / \mathrm{mL}$. However, the prevalence of colistin-resistant pathogenic $E$. coli was lower than in our study, being in only $3.2 \%$ (13/404) of the samples.

The risk exists of colistin-resistant $E$. coli strains in the broiler intestinal tract being transferred onto the surface of the meat as the carcass is processed. Monte et al. (17), who investigated fresh poultry meat sold in south-east Brazil, confirmed colistin resistance in 8 out of 41 samples (19.5\%). Apart from the $m c r-1$ gene, the isolated strains of $E$. coli also included the bla $a_{C T X-M}$ and $b l a_{C M Y-2}$ genes encoding resistance to $\beta$-lactam antibiotics. This means that poultry meat can be considered a potential source of genes of colistin resistance (17). A study published by Nguyen et al. (18), which evaluated the prevalence of the $m c r-1$ gene in broilers and pigs in southern Vietnam, detected the presence of colistin resistance genes in respectively $22.2 \%$ and $24.4 \%$ of $E$. coli isolated from the final segment of the digestive tract. The authors found no changes in the prevalence of $m c r-1$ genes during the production cycle. The median MIC was $4 \mu \mathrm{g} / \mathrm{mL}$ (18).

The presence of antibiotic-resistant bacteria is one of the key issues affecting poultry antimicrobial chemotherapy. Literature data confirm that such microorganisms are more prevalent in treated flocks than in those that have not been treated. Dheilly et al. (4) demonstrated the increased prevalence of multiresistant bacterial strains in birds treated with oxytetracycline, trimethoprim with sulphadiamethoxine, amoxicillin, or enrofloxacin. The growth of a tetracycline-resistant $E$. coli population has been reported only in birds receiving oxytetracycline, whereas multiresistant $E$. coli strains were detected in $E$. coli populations isolated from birds treated with trimethoprim with sulphadimethoxine, amoxicillin, and enrofloxacin (4). For the same geographical area, $m c r-1$-positive E. coli strains isolated from broilers in the years 2014-2016 showed greater resistance to amoxicillin than pathogenic $E$. coli strains $(100 \%$ in the experimental group vs. $73.64 \%$ ). A similar situation was observed for amoxicillin with clavulanic acid ( $28 \%$ vs. $17.20 \%)$, enrofloxacin $(76 \%$ vs. $48.65 \%)$, norfloxacin (64\% vs. $45.06 \%)$, and trimethoprim with sulphamethoxazole ( $80 \%$ vs. $46.42 \%)$.

A lower prevalence of doxycycline and neomycin insusceptibility was observed in resistant strains: $24 \%$ in the experimental group vs. $52.08 \%$ and $4 \%$ vs. $19.33 \%$, respectively. Similar data across experimental and control chicken groups were obtained for spectinomycin and florfenicol, where the values were $40 \%$ in the experimental group vs. $39.087 \%$ and $40 \%$ vs. $38.15 \%$, respectively. A total of $60 \%$ of the isolates in both groups were classified as moderately susceptible to spectinomycin, $4 \%$ in the experimental group $v s$. $3.83 \%$ to norfloxacin, $24 \%$ vs. $44.16 \%$ to florfenicol, $52 \%$ vs. $11.89 \%$ to doxycycline, and $28 \%$ vs. $9.75 \%$ to amoxicillin with clavulanic acid (14).

Antibiotics and chemotherapeutics will undoubtedly remain the main tools in fighting poultry infections in the coming years, while researchers continue to seek alternative treatment methods. Finding truly effective substitutes poses a considerable challenge for researchers investigating treatment methods that would be useful not only for poultry, but 
also for other animals, and particularly for humans. Searching for alternative treatments and creating conditions conducive to reducing the incidence of infection are the greatest imperatives to address if we are to maintain the efficacy of antibiotics. Considering that multidrug resistant strains are also present in sporadically treated flocks, we should assume that multiresistant bacteria colonise the digestive tract of birds before they are placed in the growing house.

Conflict of Interests Statement: The authors declare that there is no conflict of interests regarding the publication of this article.

Financial Disclosure Statement: The study was financially supported by the statutory funding of the Department of Genetics and Animal Breeding (No. 506.534.04.05), Poznan University of Life Sciences.

\section{Animal Rights Statement: None required.}

\section{References}

1. Baron S., Hadjadj L., Rolain J.M., Olaitan A.O.: Molecular mechanisms of polymyxin resistance: knowns and unknowns. Int J Antimicrob 2016, 48, 583-591.

2. Carvalho I.T., Santos L.: Antibiotics in the aquatic environments: a review of the European scenario. Environ Int 2016, 94, 736-757.

3. Catry B., Cavaleri M., Baptiste K., Grave K., Grein K., Holm A., Jukes H., Liebana E., Lopez Navas A., Mackay D., Magiorakos A.P., Moreno Romo M.A., Moulin G., Muñoz Madero C., Matias Ferreira Pomba M.C., Powell M., Pyörälä S., Rantala M., Ružauskas M., Sanders P., Teale C., Threlfall E.J., Törneke K., van Duijkeren E., Torren Edo J.: Use of colistin-containing products within the European Union and European Economic Area (EU/EEA): development of resistance in animals and possible impact on human and animal health. Int $\mathrm{J}$ Antimicrob Agents 2015, 46, 297-306.

4. Dheilly A., Le Devendec L., Mourand G., Bouder A., Jouy E., Kempf I.: Resistance gene transfer during treatments for experimental avian colibacillosis. Antimicrob Agents Chemother 2012, 56, 189-196

5. Elbediwi M., Li Y., Paudyal N., Pan H., Li X., Xie S., Rajkovic A., Feng Y., Fang W., Rankin S.C., Yue M.: Global Burden of Colistin-Resistant Bacteria: Mobilized Colistin Resistance Genes Study (1980-2018). Microorganisms 2019, 7 , 461.

6. Eng S.K., Pusparajah P., Ab Mutalib N.S., Ser H.L., Chan K.G., Lee L.H.: Salmonella: a review on pathogenesis, epidemiology, and antibiotic resistance. Front Life Sci 2015, 8, 284-293.

7. European Council Regulation (EC) No 1099/2009 of 24 September 2009 on the protection of animals at the time of killing. OJ L303, 18/11/2009.

8. European Medicines Agency: European Surveillance of Veterinary Antimicrobial Consumption, 2018. Sales of veterinary antimicrobial agents in 30 European countries in 2016, Eighth ESVAC Report, EMA/275982/2018. European Medicines Agency, London, 2018, pp 180. https://www.ema. europa.eu/en/documents/report/sales-veterinary-antimicrobialagents-30-european-countries-2016-trends-2010-2016-eighthesvac_en.pdf.
9. Gröndahl-Yli-Hannuksela K., Lönnqvist E., Kallonen T., Lindholm L., Jalava J., Rantakokko-Jalava K., Vuopio J.: The first human report of mobile colistin resistance gene, $m c r-1$, in Finland. APMIS 2018, 126, 413-417.

10. Haenni M., Poirel L., Kieffer N., Châtre P., Saras E., Métayer V., Dumoulin R., Nordmann P., Madec J.Y.: Co-occurrence of extended spectrum $\beta$-lactamase and MCR-1 encoding genes on plasmids. Lancet Infect Dis 2016, 16, 281-282.

11. Kaakoush N.O., Castaño-Rodríguez N., Mitchell H.M., Man S.M.: Global epidemiology of Campylobacter infection. Clin Microbiol Rev 2015, 28, 687-720.

12. Kempf I., Jouy E., Chauvin C.: Colistin use and colistin resistance in bacteria from animals. Int J Antimicrob 2016, 48 598-606.

13. Liu Y.Y., Wang Y., Walsh T.R., Yi L.X., Zhang R., Spencer J., Doi Y., Tian G., Dong B., Huang X., Yu L.F., Gu D., Ren H., Chen X., Lv L., He D., Zhou H., Liang Z., Liu J.H., Shen J.: Emergence of plasmid-mediated colistin resistance mechanism MCR-1 in animals and human beings in China: a microbiological and molecular biological study. Lancet Infect Dis 2016, 16, 161-168.

14. Majewski M., Józefiak A., Kimsa-Furdzik M., Dziubdziela L., Hudak-Nowak M., Wilczyński J., Anusz K.: Antimicrobial resistance of Escherichia coli and Klebsiella spp. conventionally sampled from factory-farmed chickens - clinical submissions. Ann Agric Environ Med 2020, doi: 10.26444/aaem/120927.

15. Matamoros S., van Hattem J.M., Arcilla M.S., Willemse N., Melles D.C., Penders J., Vinh T.N., Hoa N.T., Bootsma M.C.J, van Genderen P.J., Goorhuis A., Grobusch M., Molhoek N., OudeLashof A.M.L., Stobberingh E.E., Verbrugh H.A., de Jong M.D., Schultsz C.: Global phylogenetic analysis of Escherichia coli and plasmids carrying the $m c r-1$ gene indicates bacterial diversity but plasmid restriction. Sci Rep 2017, 7, $15364,1-10$

16. Mathers A.J., Peirano G., Pitout J.D.: The role of epidemic resistance plasmids and international high-risk clones in the spread of multidrug-resistant Enterobacteriaceae. Clin Microbiol Rev 2015, 28, 565-591.

17. Monte D.F., Mem A., Fernandes M.R., Cerdeira L., Esposito F., Galvão J.A., Franco B.D.G.M., Lincopan N., Landgraf M.: Chicken meat as a reservoir of colistin-resistant Escherichia coli strains carrying $m c r-1$ genes in South America. Antimicrob Agents Chemother 2017, 61, e02718-16, doi: 10.1128/AAC.02718-16.

18. Nguyen N.T., Nguyen H.M., Nguyen C.V., Nguyen T.V., Nguyen M.T., Thai H.Q., Ho M.H., Thwaites G., Ngo H.T., Baker S., Carrique-Mas J.: Use of colistin and other critical antimicrobials on pig and chicken farms in southern Vietnam and its association with resistance in commensal Escherichia coli bacteria. Appl Environ Microbiol 2016, 82, 3727-3735.

19. Poirel L., Kieffer N., Liassine N., Thanh D., Nordmann P.: Plasmid-mediated carbapenem and colistin resistance in a clinical isolate of Escherichia coli. Lancet Infect Dis 2016, 16 , 281, doi: 10.1016/S1473-3099(16)00006-2.

20. Rahmatallah N., Rhaffouli H., Amine I.L., Sekhsokh Y., Fihri O.F., Houadfi M.: Consumption of antibacterial molecules in broiler production in Morocco. Vet Med Sci 2018, 4, 80-90.

21. R Core Team: R: A language and environment for statistical computing. R Foundation for Statistical Computing, Vienna, 2019. https://www.R-project.org/.

22. Ronquillo M.G., Hernandez J.C.A.: Antibiotic and synthetic growth promoters in animal diets: review of impact and analytical methods. Food Control 2017, 72, 255-267.

23. Rouger A., Tresse O., Zagorec M.: Bacterial contaminants of poultry meat: sources, species, and dynamics. Microorganisms 2017, 5, 50, doi: 10.3390/microorganisms5030050.

24. Walsh T.R., Wu Y.: China bans colistin as a feed additive for animals. Lancet Infect Dis 2016, 16, 1102-1103. 
25. Wang R., van Dorp L., Shaw L.P., Bradley P., Wang Q., Wang X., Jin L., Zhang Q., Liu Y., Rieux A., Dorai-Schneiders T., Weinert L.A., Iqbal Z., Didelot X., Wang H., Balloux F.: The global distribution and spread of the mobilized colistin resistance gene $m c r-1$. Nat Commun 2018, 9, 1179, doi: 10.1038/s41467018-03205-z.

26. World Health Organisation: Critically important antimicrobials for human medicine $-5^{\text {th }}$ revision. World Health Organization, Geneva, 2017. https://www.who.int/foodsafety/publications/ antimicrobials-fifth/en/.

27. Yao X., Doi Y., Zeng L., Lv L., Liu J.H.: Carbapenem-resistant and colistin-resistant Escherichia coli co-producing NDM-9 and MCR-1. Lancet Infect Dis 2016, 16, 288-289.
28. Yassin A.K., Zhang J., Wang J., Chen L., Kelly P., Butaye P., Lu G., Gong J., Li M., Wie L., Wang Y., Qi K., Han X., Price S., Hathcock T., Wang C.: Identification and characterization of $\mathrm{mcr}$ mediated colistin resistance in extraintestinal Escherichia coli from poultry and livestock in China. FEMS Microbiol Lett 2017, 364, 1-6, doi: 10.1093/femsle/fnx242.

29. Zurfuh K., Poirel L., Nordmann P., Nüesch-Inderbinen M., Hächler H., Stephana R.: Occurrence of the plasmid-borne $m c r-1$ colistin resistance gene in extended-spectrum $\beta$-lactamaseproducing Enterobacteriaceae in river water and imported vegetable samples in Switzerland. Antimicrob Agents Chemother 2016, 60, 2594-2595. 